\title{
Note on the Text and Translation
}

Sorel's "Étude sur Vico" appeared in le Devenir social over three installments in October, November, and December 1896. This original publication can be accessed through Gallica.fr. Sorel often republished in book form material that had first appeared in a periodical, sometimes with significant revisions. This was not, however, the case with the "Étude." Since no manuscript has survived, the text itself presents few problems. Anne-Sophie Menasseyre prepared in 2007 a critical edition of the essay together with a substantial introduction and annotations, which have been of great help to the present work.

The "Étude" has never before appeared in English. A few points about the principles of the present translation are worth making.

Much of Sorel's text consists of quotations from Vico, which is to say quotations from Jules Michelet's 1827 translations of Vico, in the edition published as part of Michelet's collected works in 1894. Cristina Belgioioso, who re-translated the New Science into French in 1844, wrote in her introduction that Michelet's "fidelity to Vico ... prevented him from clarifying the obscure passages, without always obliging him to render them as Vico had written them." Indeed Michelet's Vico is notoriously and successfully free with the original. We therefore translate quoted passages directly from Michelet's French. We note discrepancies between Michelet's text and Sorel's quotations where they occur and provide - where possible - references to Nicolini's standard paragraph numbering of the New Science (marked with a §), also used in Thomas Bergin and Max Fisch's English translation, or page numbers in standard English translations of other works. Square brackets $[. .$.$] enclose these and other editorial$ insertions.

Sorel's placement of footnotes-generally just before the quotation they source - was likely to be extremely distracting for any contemporary reader. Since no meaning hangs on the placement of notes simply containing a citation, we have silently regularized them. However, in some cases, where Sorel appends a note to a word, even inside a quotation, we have left the note in its original location. Sorel's references are not always complete-in the bibliography for the "Study" we have collected all the texts he cites in the editions he used or seems most likely to have used.

In general, this translation prefers English cognates for Sorel's and Michelet's terms. In this it follows the principles of the Bergin and Fisch rather than the Marsh New Science.

1 G.B. Vico, La science nouvelle. Translated by Cristina Belgioioso (Paris: Renouard, 1844), cxviii.

(C) ERIC BRANDOM AND TOMMASO GIORDANI, 2020 | DOI:10.1163/9789004416338_004

This is an open access chapter distributed under the terms of the GC-BY-NC 4.9 License. 
Sorel's prose style was not considered polished in its time and may appear to modern readers of English as genuinely unfinished. He makes heavy use of semi-colons and dashes, often resulting in long sentences that in English would be implausible or at least burdensome. We have therefore not always respected Sorel's use of punctuation or sentence divisions. Belgioioso's censure of Michelet's translation, however, we hope does not here apply.

Finally, although apportioning credit in any co-authored text is tricky and responsibility rests entirely on all heads, it should be said that Tommaso Giordani did the majority of the work on the introduction, as Eric Brandom did for the translation. 